\title{
Puffed cereals with added chamomile - quantitative analysis of polyphenols and optimization of their extraction method
}

\author{
Tomasz Blicharski', Anna Oniszczuk², Marta Olech ${ }^{3}$, Tomasz Oniszczuk ${ }^{4}$, Agnieszka Wójtowicz ${ }^{4}$, \\ Wojciech Krawczyk ${ }^{5}$, Renata Nowak ${ }^{3}$ \\ ${ }^{1}$ Department of Rehabilitation and Orthopedics, Medical University of Lublin, Poland \\ ${ }^{2}$ Department of Inorganic Chemistry, Medical University, Lublin, Poland \\ ${ }^{3}$ Department of Pharmaceutical Botany, Medical University, Lublin, Poland \\ ${ }^{4}$ Department of Food Process Engineering, University of Life Sciences, Lublin, Poland \\ ${ }^{5}$ Department of Expert Medical Assistance with Emergency Medicine Unit, Medical University, Lublin, Poland
}

Blicharski T, Oniszczuk A, Olech M, Oniszczuk T, Wójtowicz A, Krawczyk W, Nowak R. Puffed cereals with added chamomile - quantitative analysis of polyphenols and optimization of their extraction method. Ann Agric Environ Med. 2017; 24(2): 222-228. doi: 10.5604/12321966.1233564

\begin{abstract}
Introduction. Functional food plays an important role in the prevention, management and treatment of chronic diseases. One of the most interesting techniques of functional food production is extrusion-cooking. Functional foods may include such items as puffed cereals, breads and beverages that are fortified with vitamins, some nutraceuticals and herbs. Due to its pharmacological activity, chamomile flowers are the most popular components added to functional food.

Objective. Quantitative analysis of polyphenolic antioxidants, as well as comparison of various methods for the extraction of phenolic compounds from corn puffed cereals, puffed cereals with an addition of chamomile $(3,5,10$ and $20 \%)$ and from Chamomillae anthodium.

Materials and Methods. Two modern extraction methods - ultrasound assisted extraction (UAE) at $40^{\circ} \mathrm{C}$ and $60^{\circ} \mathrm{C}$, as well as accelerated solvent extraction (ASE) at $100^{\circ} \mathrm{C}$ and $120^{\circ} \mathrm{C}$ were used for the isolation of polyphenols from functional food. Analysis of flavonoids and phenolic acids was carried out using reversed-phase high-performance liquid chromatography and electrospray ionization mass spectrometry (LC-ESI-MS/MS).

Results and Conclusions. For most of the analyzed compounds, the highest yields were obtained by ultrasound assisted extraction. The highest temperature during the ultrasonification process $\left(60^{\circ} \mathrm{C}\right)$ increased the efficiency of extraction, without degradation of polyphenols. UAE easily arrives at extraction equilibrium and therefore permits shorter periods of time, reducing the energy input. Furthermore, UAE meets the requirements of 'Green Chemistry'.
\end{abstract}

\section{Key words}

Matricaria chamomilla, functional food, polyphenolic antioxidants, LC-ESI-MS/MS analysis, extraction methods

\section{INTRODUCTION}

A functional food (medical food), is a natural or processed food that contains well-known biologically-active compounds to ensure or enhance health or well-being. Thus, functional food plays an important role in the prevention, management and treatment of chronic diseases of the modern age [1, 2]. The functional food market is growing worldwide and new products are continuously being launched [3]. Various drivers, such as increased life expectancy and rising costs of healthcare are likely to contribute to the future growth in this product segment [4].

One of the most interesting techniques of functional food production is extrusion-cooking [5]. This method is convenient from the nutritional and economic point of view because it produces a stable product with all nutritive components preserved or enhanced $[6,7]$. During extrusion-cooking, the raw materials are subjected to high temperature, high pressure, and severe shear forces $[6,8]$. Extrusion-cooking seems to be one of the best methods for obtaining the maximum nutritive

Address for correspondence: Anna Oniszczuk, Department of Inorganic Chemistry, Medical University, Chodźki 4a, 20-093 Lublin, Poland

Tel.: +48 817564836. Fax: +48 815357378

E-mail: anoniszczuk@o2.pl

Received: 26 October 2015; accepted: 18 May 2016; first published on February 2017 value of several plant materials. Prevention or reduction of nutrient destruction, together with improvements in starch or protein digestibility, is clearly of importance in most extrusion applications [6]. Functional foods may include such items as puffed cereals, breads and beverages that are fortified with vitamins, some nutraceuticals and herbs.

Chamomile (Matricaria chamomilla L.), a member of the Asteraceae family, is one of the oldest medicinal plants, widely used throughout the world for a variety of healing applications. The components extracted from chamomile flowers possess anti-inflammatory, anti-allergic, antispasmodic, anti-bacterial, anti-pyretic, anti-fungal, sedative, analgesic, antioxidant, antiparasitic, antiaging, and anticancer properties [9-12]. Flavonoids, phenolic acids, sesquiterpens and coumarins are considered to be the major bioactive compounds of this plant [13]. The consumption of chamomile as tea is rated at more than one million cups per day [14]. Due to its pharmacological activity, chamomile flowers are the most popular components added to functional food. Puffed cereals and gruels enriched with a $10 \%$ and $20 \%$ addition of Matricaria chamomilla, produced by us, possess high radical scavenging properties [12]. Therefore, it is very important to determine if the puffed cereal compounds possess antioxidant activity. However, it is well known that depending on the manner of preparation, extracts may 
produce different effects. For that reason, it is very important to find an optimal extraction method for obtaining extracts with the highest content of biologically active, especially antioxidant, compounds and the lowest content of interfering substances [15-18].

\section{OBJECTIVE}

The objective of the study was quantitative analysis (LC-ESIMS/MS) of polyphenolic antioxidants, as well as comparison of various extraction methods for the extraction of phenolic compounds from corn puffed cereals, puffed cereals with an addition of chamomile (3, 5, 10 and 20\%) and from Chamomillae anthodium.

Cereals were produced in the Department of Food Process Engineering, University of Life Sciences in Lublin.

\section{MATERIAL AND METHODS}

Chemicals And Instruments. Analytical grade standards of flavonoids and phenolic acids, as well as liquid chromatography grade (LC) acetonitrile were purchased from Sigma-Aldrich Fine Chemicals (St. Louis, MO, USA). LC grade methanol and analytical grade ethanol were obtained from J.T. Baker (Phillipsburg, USA). LC grade water was prepared using a Millipore Direct-Q3 purification system (Bedford, MA, USA). The SPE columns were Bakerbond C18, $3 \mathrm{~mL}$ containing $500 \mathrm{mg}$ end-capped, $40 \mu \mathrm{m}$ reversed phase packing (J.T. Baker, The Netherlands).

Plant Materials. Chamomillae anthodium was obtained from 'Kawon-Hurt' herbal industrial (Gostyń, Poland). Plant material was dried in the air, in the shade, at an average temperature $29.0 \pm 0.5^{\circ} \mathrm{C}$ Before the extraction, dry chamomile was milled and sieved.

Production of puffed cereal. Corn grit and chamomile inflorescence were blended before the extrusion process with the addition of water for initial mixture moisture content of $16 \%$. Moistened mixtures were processed with a single screw extruder TS-45 (Metalchem, Gliwice, Poland) with a configuration of $\mathrm{L} / \mathrm{D}=12$ and diameter of the forming die $\varphi=3 \mathrm{~mm}$, at a temperature of $120^{\circ} \mathrm{C}$ and constant screw speed of $125 \mathrm{rpm}$. The product was ground in a laboratory grinder iG5A (TestChem, Poland) to a particle size of less than $1 \mathrm{~mm}$ for instant grits [7].

Ultrasound assisted extraction (UAE). Extraction was performed in an ultrasonic bath (Bandelin Electronic, Germany, $20 \mathrm{kHz}, 100 \mathrm{~W}$ ) for $30 \mathrm{~min}$ at $60^{\circ} \mathrm{C}$ and $40^{\circ} \mathrm{C}$. $2 \mathrm{~g}$ portions of each sample - corn puffed cereals, puffed cereals with an addition of chamomile (3, 5, 10 and 20\%) and Chamomillae anthodium was extracted with $40 \mathrm{~mL}$ of ethanol [17]. Extracts were filtered, combined and evaporated until dry. The residues were dissolved in $10 \mathrm{~mL}$ of methanol. The procedure was repeated 3 times.

Accelerated solvent extraction (ASE). ASE was carried out with a Dionex ASE 200 instrument (Sunnyvale, CA, USA) with solvent controller. Plant material ( $2 \mathrm{~g})$ was extracted with ethanol. The extractions were performed at 2 temperatures -
100 and $120^{\circ} \mathrm{C}$, at a pressure of 60 bar for $30 \mathrm{~min}$ ( 3 cycles for $10 \mathrm{~min}$ at the same temperature, for every sample). Extracts were combined and evaporated until dry. The residues were dissolved in $10 \mathrm{~mL}$ of methanol. The whole procedure was repeated 3 times for each solvent [17].

Solid phase extraction (SPE). Crude extracts were purified using solid phase extraction. $5 \mathrm{~mL}$ of every sample was passed through a previously conditioned SPE C18 column. Polyphenols were eluted with $5 \mathrm{~mL}$ of $60 \%$ aqueous methanol and next with $10 \mathrm{~mL}$ of $30 \%$ aqueous methanol. The samples were evaporated to dryness and dissolved in $10 \mathrm{~mL}$ of methanol. The procedure was repeated 3 times [17].

LC-ESI-MS/MS conditions of analysis of phenolic compounds. Analysis of flavonoids and phenolic acids was carried out using reversed-phase high-performance liquid chromatography and electrospray ionization mass spectrometry (LC-ESI-MS/MS). Agilent 1200 Series HPLC system (Agilent Technologies, USA) equipped with a binary gradient solvent pump, a degasser, an auto sampler and column oven connected to 3200 QTRAP Mass spectrometer (AB Sciex, USA) was used.

Chromatographic separations of phenolic acids were performed according to the method previously described by Nowacka et al. [19] with slight modifications on a Zorbax SB-C18 column $(2.1 \times 50 \mathrm{~mm}, 1.8-\mu \mathrm{m}$ particle size (Agilent Technologies, USA). Bi-distilled water containing $0.1 \%$ $\mathrm{HCOOH}(\mathrm{A})$ and methanol containing $0.1 \% \mathrm{HCOOH}(\mathrm{B})$ were used as the mobile phase in gradient separations. The flow rate was $450 \mu \mathrm{L} \mathrm{min}{ }^{-1}$, injection volume $3 \mu \mathrm{L}$ and temperature of the column was $25^{\circ} \mathrm{C}$. Gradient programme was optimized as follows: $0-0.8 \mathrm{~min}-5 \% \mathrm{~B} ; 2-3 \mathrm{~min}-20 \% \mathrm{~B}$; $5.5-8 \mathrm{~min}-85 \% \mathrm{~B}$; $9.5-12 \mathrm{~min}-5 \% \mathrm{~B}$.

The QTRAP-MS system was equipped with electrospray ionization source (ESI) operated in the negative-ion mode. Chromatographic separations of flavonoid glycosides were carried out at $25^{\circ} \mathrm{C}$ on an Eclipse XDB-C18 column $(4.6 \times$ $150 \mathrm{~mm}, 5-\mu \mathrm{m}$ particle size (Agilent Technologies, USA), with a mobile phase consisting of water containing $0.1 \% \mathrm{HCOOH}$ (solvent $\mathrm{A}$ ) and acetonitrile containing $0.1 \% \mathrm{HCOOH}$ (solvent B), using $5 \mu \mathrm{L}$ injections. The flow rate was $400 \mu \mathrm{L} \mathrm{min}^{-1}$ and the gradient: $0-1 \mathrm{~min}-18 \% \mathrm{~B} ; 1.5-5.5 \mathrm{~min}$.

ESI worked at the following conditions: capillary temperature $500^{\circ} \mathrm{C}$, curtain gas at $20 \mathrm{psi}$, nebulizer gas at $50 \mathrm{psi}$, negative ionization mode source voltage $-4500 \mathrm{~V}$.

Nitrogen was used as curtain and collision gas. For each compound, the optimum conditions of Multiple Reaction Mode (MRM) were determined in the infusion mode. The data was acquired and processed using Analyst 1.5 software (AB Sciex, USA). Triplicate injections were made for each standard solution and sample. The analytes were identified by comparing retention time and $\mathrm{m} / \mathrm{z}$ values obtained by MS and $\mathrm{MS}^{2}$ with the mass spectra from corresponding standards tested under the same conditions (Tab. 1). The calibration curves obtained in MRM mode were used for quantification of all analytes [19].

The limits of detection (LOD) and quantification (LOQ) for phenolic compounds were determined at a signal-to-noise ratio of 3:1 and 10:1, respectively. Parameters of LC-MS/MS quantitative method - data for calibration curves, limit of detection (LOD) and limit of quantification (LOQ) values for each analyzed phenolic compounds are presented in Table 2. 
Table 1. LC-ESI-MS/MS analytical results of analyzed polyphenols. Compounds confirmed by comparison with authentic standards [17]

\begin{tabular}{|c|c|c|c|c|}
\hline Compound & $\begin{array}{c}\text { TR } \\
{[\mathrm{min}]}\end{array}$ & {$[\mathrm{M}-\mathrm{H}]-$} & $\begin{array}{l}\text { Fragment } \\
\text { ions }\end{array}$ & $\begin{array}{c}\text { Collision energy } \\
{[\mathrm{eV}]}\end{array}$ \\
\hline \multirow{2}{*}{ Protocatechuic acid } & \multirow{2}{*}{1.73} & \multirow{2}{*}{152.9} & 107.8 & -38 \\
\hline & & & 80.9 & -26 \\
\hline \multirow{2}{*}{ Gentisic acid } & \multirow[b]{2}{*}{2.73} & \multirow[b]{2}{*}{152.8} & 107.9 & -36 \\
\hline & & & 81 & -30 \\
\hline 4-OH-benzoic acid & 3.40 & 136.8 & 92.9 & -18 \\
\hline \multirow{2}{*}{ Vanillic acid } & \multirow{2}{*}{4.72} & \multirow{2}{*}{166.8} & 107.9 & -18 \\
\hline & & & 123 & -12 \\
\hline \multirow{2}{*}{ Caffeic acid } & \multirow{2}{*}{4.92} & \multirow{2}{*}{178.7} & 134.9 & -16 \\
\hline & & & 88.9 & -46 \\
\hline \multirow{2}{*}{ Syringic acid } & \multirow{2}{*}{5.57} & \multirow{2}{*}{196.9} & 181.9 & -12 \\
\hline & & & 122.8 & -24 \\
\hline \multirow{2}{*}{ p-Coumaric acid } & \multirow{2}{*}{6.01} & \multirow{2}{*}{162.7} & 119 & -14 \\
\hline & & & 93 & -44 \\
\hline \multirow[t]{2}{*}{ Salicylic acid } & 6.20 & 136.8 & 93 & -16 \\
\hline & & & 75 & -48 \\
\hline \multirow{2}{*}{ Ferulic acid } & \multirow{2}{*}{6.28} & \multirow{2}{*}{192.8} & 177.9 & -12 \\
\hline & & & 133.9 & -16 \\
\hline \multirow{2}{*}{ Synapic acid } & \multirow{2}{*}{6.33} & \multirow{2}{*}{222.8} & 148.9 & -20 \\
\hline & & & 121 & -36 \\
\hline \multirow{2}{*}{ Rosmarinic acid } & \multirow{2}{*}{6.60} & \multirow{2}{*}{358.7} & 160.8 & -20 \\
\hline & & & 132.6 & -44 \\
\hline Rutin & 9.68 & 608.7 & 299.6 & -46 \\
\hline & & & 270.9 & -60 \\
\hline Hyperoside & 11.30 & 462.7 & 299.7 & -28 \\
\hline & & & 254.7 & -42 \\
\hline Isoquercetin & 11.63 & 462.7 & 299.7 & -30 \\
\hline & & & 270.7 & -44 \\
\hline Kaempferol-3-rutinoside & 12.55 & 592.7 & 284.8 & -38 \\
\hline & & & 226.7 & -68 \\
\hline Astragalin & 13.52 & 446.7 & 254.8 & -40 \\
\hline & & & 226.8 & -54 \\
\hline Ouercitrin & 1432 & 4468 & 299.7 & -30 \\
\hline & T.J.J2 & Tho.0 & 270.7 & -40 \\
\hline Apigenin-7-glucoside & 14.54 & 430.7 & 267.7 & -38 \\
\hline & & & 116.9 & -84 \\
\hline Tilingcide & 1750 & 5078 & 284.8 & -30 \\
\hline Tilliroside & 17.59 & 592.8 & 254.7 & -30 \\
\hline
\end{tabular}

\section{RESULTS AND DISCUSSION}

Antioxidants are substances that reduces oxidative damage caused by free radicals which ultimately result in chronic diseases [2]. Besides antioxidant activity, phenolic acids and flavonoids have been reported to have multiple pharmacological activities [20-23]. Therefore, it is important to provide a high content of polyphenols in food. These substances are often thermolabile and may decompose
Table 2. Analytical parameters of LC-MS/MS quantitative method values for each analyzed polyphenols [17]

\begin{tabular}{|c|c|c|c|c|c|}
\hline Compound & $\begin{array}{l}\mathrm{LOD}^{*} \\
{[\mathrm{ng}} \\
\left.\mu \mathrm{L}^{-1}\right]\end{array}$ & $\begin{array}{c}\mathrm{LOQ}^{* *} \\
{[\mathrm{ng}} \\
\left.\mu \mathrm{L}^{-1}\right]\end{array}$ & 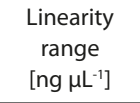 & $\mathrm{R}^{2}$ & Regression equation \\
\hline $\begin{array}{l}\text { Proto- } \\
\text { catechuic acid }\end{array}$ & 0.010 & 0.020 & $0.05-25.00$ & 0.9995 & $y=48.5 x+9.41 e+003$ \\
\hline Gentisic acid & 0.008 & 0.015 & $0.025-25.00$ & 0.9997 & $y=409 x-3.16 e+004$ \\
\hline $\begin{array}{l}\text { 4-OH-benzoic } \\
\text { acid }\end{array}$ & 0.040 & 0.080 & $0.05-5.00$ & 0.9992 & $y=597 x+2.1 e+004$ \\
\hline Vanillic acid & 0.050 & 0.100 & $0.1-50.00$ & 0.9992 & $y=73.1 x+3.67 e+003$ \\
\hline Caffeic acid & 0.040 & 0.060 & $0.05-1.00$ & 0.9985 & $\begin{aligned} y= & 1.39 e+003 x+ \\
& 3.28 e+004\end{aligned}$ \\
\hline Syringic acid & 0.050 & 0.100 & $0.1-50.00$ & 0.9994 & $\begin{aligned} y= & 1.39 e+003 x+ \\
& 3.28 e+004\end{aligned}$ \\
\hline $\begin{array}{l}\text { p-Coumaric } \\
\text { acid }\end{array}$ & 0.050 & 0.100 & $0.125-2.50$ & 0.9988 & $y=794 x+8.47 e+004$ \\
\hline Salicylic acid & 0.020 & 0.050 & $0.05-1.00$ & 0.9991 & $\begin{aligned} y= & 3.23 e+003 x+ \\
& 2.83 e+005\end{aligned}$ \\
\hline Ferulic acid & 0.010 & 0.025 & $0.05-5.00$ & 0.9996 & $y=380 x+2.01 e+004$ \\
\hline Synapic acid & 0.010 & 0.025 & $0.025-5.00$ & 0.9980 & $y=119 x-226$ \\
\hline $\begin{array}{l}\text { Rosmarinic } \\
\text { acid }\end{array}$ & 0.010 & 0.020 & $0.025-12.50$ & 0.9996 & $y=284 x-1.65 e+003$ \\
\hline Rutin & 0.005 & 0.010 & $0.02-2.5$ & 0.9983 & $y=280 x-8.49 e+003$ \\
\hline Hyperoside & 0.010 & 0.020 & $0.05-2.5$ & 0.9987 & $y=354 x-185$ \\
\hline Isoquercetin & 0.008 & 0.020 & $0.05-2.5$ & 0.9991 & $y=353 x-498$ \\
\hline $\begin{array}{l}\text { Kaempferol-3- } \\
\text { rutinoside }\end{array}$ & 0.001 & 0.003 & $0.05-2.5$ & 0.9975 & $y=639 x-1.11 e+004$ \\
\hline Astragalin & 0.002 & 0.004 & $0.01-2.5$ & 0.9992 & $y=935 x+1.15 e+004$ \\
\hline $\begin{array}{l}\text { Apigenin-7- } \\
\text { glucoside }\end{array}$ & 0.0005 & 0.001 & $0.005-1.00$ & 0.9992 & $\begin{array}{c}y=3.02 e+003 x+ \\
1.4 e+004\end{array}$ \\
\hline
\end{tabular}

*LOD- limit of detection; **LQ- limi

during the processing of plant materials. For that reason, it is appropriate to develop technology for food production and extraction of phenolic compounds. This minimizes the degradation of bioactive compounds, reduces analysis costs, requires less laboratory work, and can produce high purity compounds in the extraction yield [24].

In the presented study, 2 modern extraction methods - ultrasound assisted extraction at $40^{\circ} \mathrm{C}$ and $60^{\circ} \mathrm{C}$ and accelerated solvent extraction at $100^{\circ} \mathrm{C}$ and $120^{\circ} \mathrm{C}$ were used for the isolation of polyphenols from functional food.

The qualitative and quantitative composition of extracts from puffed cereals with the addition of chamomile, obtained by various extraction methods, was different (Tab. 3-4). Both the qualitative and quantitative content of polyphenols increased with the addition of linden inflorescence. The following phenolic acids were identified in the chamomile extract, as well as in the extracts with 10 and $20 \%$ addition of chamomile: protocatechuic, gentisic, 


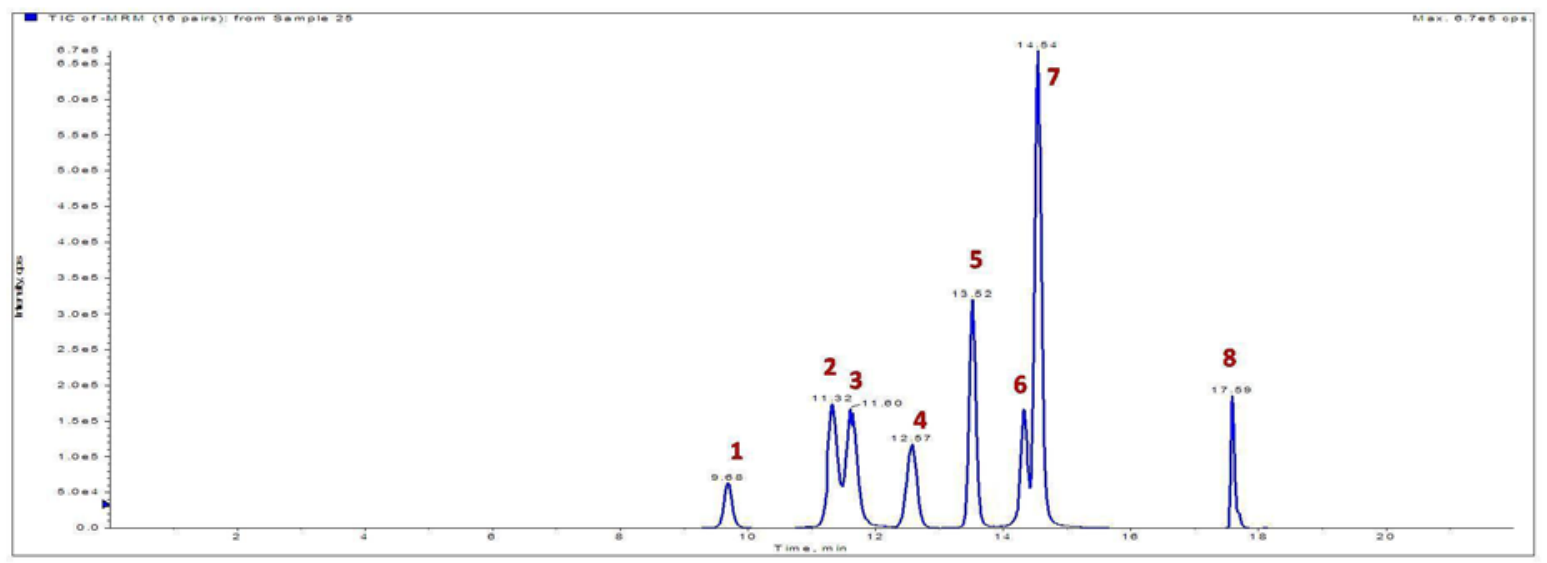

Figure 1. Exemplary LC-ESI-MS/MS chromatogram of analyzed flavonoid standards. 1) Rutin, 2) Hyperoside, 3) Isoquercetin, 4) Kaempferol-3-rutinoside, 5) Astragalin, 6) Quercitrin, 7) Apigenin-7-glucoside, 8) Tiliroside. See Experimental section for details

4-OH-benzoic acid, vanillic, caffeic, syryngic, $p$-coumaric, salicylic, ferulic, synaptic and rosmarinic. The same extracts also confirmed the content of flavonoids: rutin, hyperoside, isoquercetin, kaempferol-3-rutinoside, astragalin and apigenin-7-glucoside. However, in corn gruel containing $3 \%$ of Chamomillae anthodium, hyperoside, kaempferol-3rutinoside, astragalin and synaptic acid were not detected. In a similar manner, changed properties of analyzed samples - the instant gruel containing 3\% linden inflorescence, did not exhibit antioxidant activity, while the product with a $20 \%$ addition of chamomile scavenged free radicals very well [12].

For most of the analyzed compounds, the highest yields were obtained by ultrasound assisted extraction. For caffeic acid and astragalin only, the most efficient method was accelerated solvent extraction at $100^{\circ} \mathrm{C}$. The highest temperature during the ultrasonification process $\left(60^{\circ} \mathrm{C}\right)$ increased the efficiency of extraction, without degradation of polyphenols.

UAE can provide a high yield of analyzed substances in a short amount of time. It reduces the volume of solvent, requires lower energy input, simple manipulation, high reproducibility and meets the requirements of "Green Chemistry" [25]. The enhancement of extraction efficiency of organic compounds by ultrasound is implied to the cavitation. This phenomenon can cause locally high temperatures and pressures which may accelerate extraction of compounds [26-28]. Moreover, ultrasound can penetrate the matrix material, rupturing the cell walls, resulting in extracted compounds being more easily released from the matrix into the extraction medium [27].

The results of a recent study confirm that UAE is an effective, easy to operate, reliable, and feasible method for extraction of phenolic compounds from functional food [24] and from plant material [29, 30]. The comparison between the ultrasound-assisted extraction, and different extraction methods showed the superiority of UAE for extracting polyphenols. For example, from Thymus vulgaris L. herb, Verbena officinalis L. flowers [31], Phlomidoschema parviflorum L. leaves [32] and Vitis vinifera L. seeds [33].

Ethanol used in experiment as an extractant, is characterized by insignificant toxicity and environmental compatibility. This solvent is recommended by the US Food and Drug Administration for extraction purposes [28].

\section{CONCLUSIONS}

The techniques used in this study proved to be a repeatable method, as indicated by the values of standard deviation (Tab. 3-4). Recoveries ranged from 91.7\% ( $p$-coumaric) $101.6 \%$ (apigenin-7-glucoside), demonstrating the method's accuracy.

Unprocessed herbs, fruits and vegetables can be a source of many compounds that have antioxidant properties with no negative influence on antioxidant activity in the compounds present in the raw material. The findings of the current study demonstrate that the high-temperature extrusion-cooking process and extraction methods used do not deactivate polyphenolic antioxidant compounds, which were present in raw Chamomillae anthodium.

The results of this present study indicate that the most effective technique for the isolation of analyzed phenolic compounds from chamomile and puffed cereal, enriched with chamomile, was UAE (using $80 \%$ aqueous ethanol, extraction time $60 \mathrm{~min}$, ultrasound frequency $20 \mathrm{kHz}$ and power $100 \mathrm{~W})$. The relatively low ultrasound frequency $(20 \mathrm{kHz})$ and short extraction time could limit the degradation of analyzed compounds during extraction. The results indicate that the UAE easily arrives at extraction equilibrium, and therefore permits shorter periods of time, reducing the energy input. Furthermore, UAE meets the requirements of 'Green Chemistry'.

The study shows that extrusion cooking would produce a wide range of products containing antioxidant active polyphenols, because it has no negative influence on polyphenolic compounds which are present both in the raw and enriched with the Matricaria chamomilla final products.

\section{REFERENCES}

1. Diplock AT, Aggett PJ, Ashwell, M, Bornet F, Fern EB, Roberfroid MB. Scientific concepts of functional foods in Europe. Consensus document. Br J Nutr. 1999; 81(4): 1-27.

2. Butnariu M, CauniiA. Design management of functional foods for quality of life improvement. Ann Agric Environ Med. 2013; 20(4):736741

3. Bigliardi B, Galati, F. Innovation trends in the food industry. The case of functional foods. Trends Food Sci Tech. 2013; 31(2): 118-129. 
Table 3. Phenolic acids content $(n=3)$

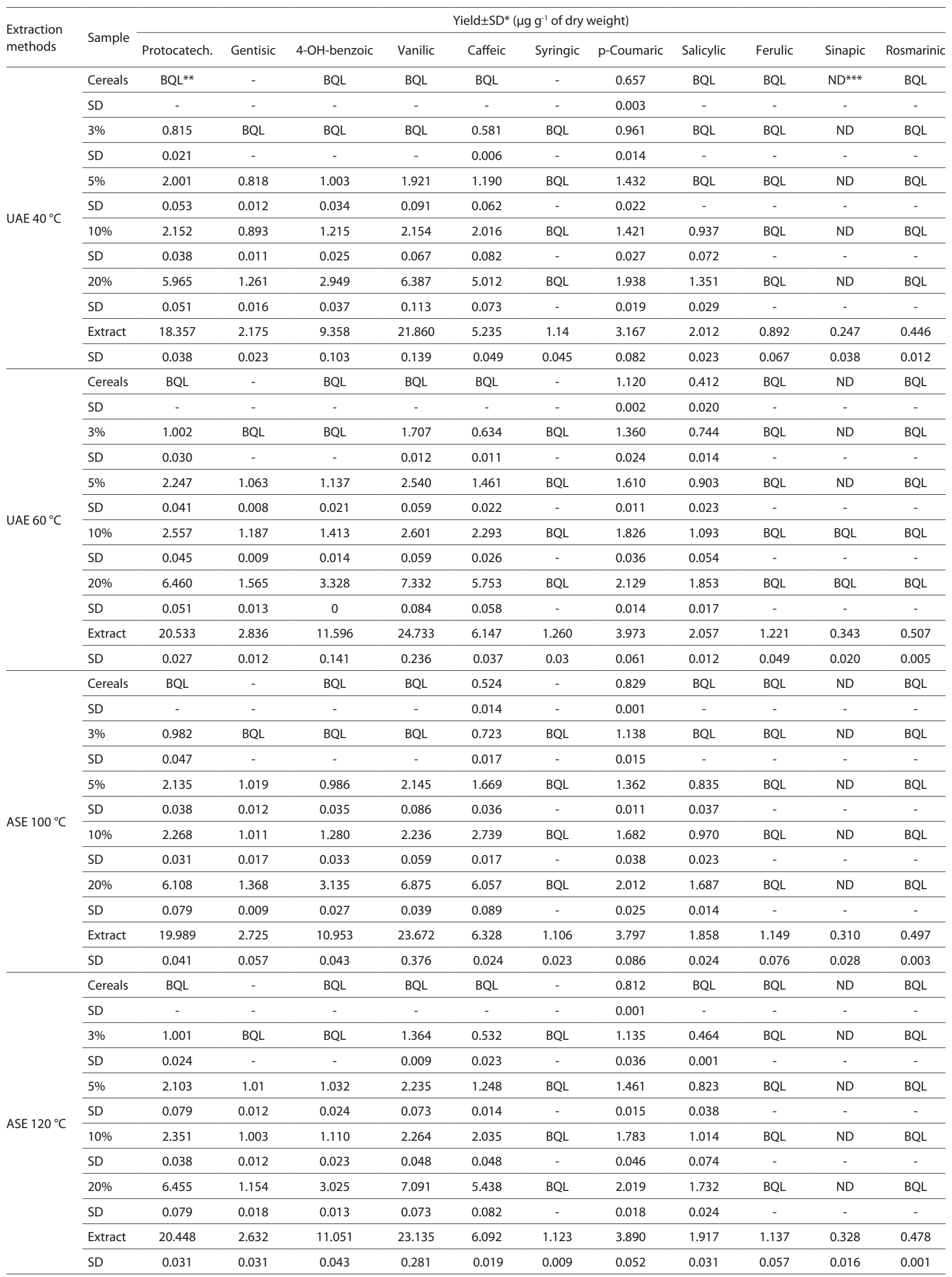

*SD - standard deviation $(n=3)$; ** BQL - peak detected, concentration lower than the LOQ but higher than the LOD; ***ND - peak not detected 
Table 4. Flavonoids content $(n=3)$

\begin{tabular}{|c|c|c|c|c|c|c|c|}
\hline \multirow[b]{2}{*}{$\begin{array}{l}\text { Extraction } \\
\text { method }\end{array}$} & \multirow[b]{2}{*}{ Sample } & \multicolumn{6}{|c|}{ Yield $\pm \mathrm{SD}^{*}$ ( $\mu \mathrm{g} \mathrm{g}^{-1}$ of dry weight) } \\
\hline & & 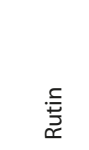 & 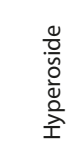 & 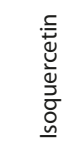 & 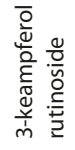 & 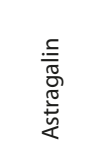 & 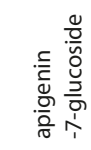 \\
\hline \multirow{12}{*}{ UAE $40^{\circ} \mathrm{C}$} & Cereals & $N D^{* * *}$ & ND & ND & ND & ND & ND \\
\hline & SD & - & - & - & - & - & - \\
\hline & $3 \%$ & $\mathrm{BQL}^{* *}$ & ND & $\mathrm{BQL}$ & ND & ND & 2.006 \\
\hline & SD & - & - & - & - & - & 0.027 \\
\hline & $5 \%$ & 2.261 & $\mathrm{BQL}$ & $\mathrm{BQL}$ & ND & $\mathrm{BQL}$ & 3.713 \\
\hline & SD & 0.032 & - & - & - & - & 0.062 \\
\hline & $10 \%$ & 4.057 & BQL & 0.586 & ND & BQL & 46.801 \\
\hline & SD & 0.089 & - & 0.014 & - & - & 0.763 \\
\hline & $20 \%$ & 4.832 & $\mathrm{BQL}$ & 2.113 & $\mathrm{BQL}$ & 0.912 & 83.891 \\
\hline & SD & 0.056 & - & 0.021 & - & 0.034 & 0.435 \\
\hline & Extract & 44.383 & 12.687 & 22.617 & $\mathrm{BQL}$ & 13.871 & 441.972 \\
\hline & SD & 0.432 & 0.397 & 0.320 & - & 0.324 & 0.826 \\
\hline \multirow{12}{*}{ UAE $60^{\circ} \mathrm{C}$} & Cereals & 2.351 & ND & ND & ND & ND & 1.525 \\
\hline & SD & 0.041 & - & - & - & - & 0.023 \\
\hline & $3 \%$ & 2.853 & ND & $\mathrm{BQL}$ & ND & ND & 2.169 \\
\hline & SD & 0.009 & - & - & - & - & 0.037 \\
\hline & $5 \%$ & 3.567 & $\mathrm{BQL}$ & $\mathrm{BQL}$ & ND & $\mathrm{BQL}$ & 4.133 \\
\hline & SD & 0.047 & - & - & - & - & 0.047 \\
\hline & $10 \%$ & 4.742 & $\mathrm{BQL}$ & 0.621 & $\mathrm{BQL}$ & 0.354 & 47.046 \\
\hline & SD & 0 & - & 0 & - & 0.051 & 0.661 \\
\hline & $20 \%$ & 5.361 & 0.541 & 2.357 & $\mathrm{BQL}$ & 1.158 & 87.021 \\
\hline & SD & 0.062 & 0.011 & 0 & - & 0.042 & 0.501 \\
\hline & Extract & 46.233 & 14.767 & 23.467 & $\mathrm{BQL}$ & 14.334 & 460.333 \\
\hline & SD & 0.249 & 0.169 & 0.205 & - & 0.249 & 1.027 \\
\hline \multirow{12}{*}{ ASE $100^{\circ} \mathrm{C}$} & Cereals & ND & ND & ND & ND & ND & ND \\
\hline & SD & - & - & - & - & - & - \\
\hline & $3 \%$ & $\mathrm{BQL}$ & ND & $\mathrm{BQL}$ & ND & ND & 1.931 \\
\hline & SD & - & - & - & - & - & 0.029 \\
\hline & $5 \%$ & 2.261 & $\mathrm{BQL}$ & $\mathrm{BQL}$ & ND & 0.327 & 4.013 \\
\hline & SD & 0.083 & - & - & - & 0.012 & 0.055 \\
\hline & $10 \%$ & 4.389 & BQL & 0.582 & ND & 0.420 & 46.702 \\
\hline & SD & 0.049 & - & 0.019 & - & 0.051 & 0.163 \\
\hline & $20 \%$ & 5.147 & 0.492 & 2.039 & $\mathrm{BQL}$ & 1.351 & 86.220 \\
\hline & SD & 0.068 & 0.012 & 0.023 & - & 0.042 & 0.453 \\
\hline & Extract & 45.671 & 14.222 & 22.146 & $\mathrm{BQL}$ & 14.931 & 451.572 \\
\hline & SD & 0.357 & 0.119 & 0.224 & - & 0.109 & 0.994 \\
\hline \multirow{12}{*}{ ASE $120^{\circ} \mathrm{C}$} & Cereals & ND & ND & ND & ND & ND & ND \\
\hline & SD & - & - & - & - & - & - \\
\hline & $3 \%$ & $\mathrm{BQL}$ & ND & $\mathrm{BQL}$ & ND & ND & 1.814 \\
\hline & SD & - & - & - & - & - & 0.039 \\
\hline & $5 \%$ & 2.162 & $\mathrm{BQL}$ & $\mathrm{BQL}$ & ND & $\mathrm{BQL}$ & 3.913 \\
\hline & SD & 0.039 & - & - & - & - & 0.092 \\
\hline & $10 \%$ & 4.273 & $\mathrm{BQL}$ & 0.563 & ND & $\mathrm{BQL}$ & 45.920 \\
\hline & SD & 0.019 & - & 0.029 & - & - & 0.695 \\
\hline & $20 \%$ & 5.032 & BQL & 1.939 & $\mathrm{BQL}$ & 1.017 & 87.0 \\
\hline & SD & 0.016 & - & 0.032 & - & 0.081 & 0.658 \\
\hline & Extract & 43.298 & 12.987 & 22.346 & $\mathrm{BQL}$ & 13.925 & 449.331 \\
\hline & SD & 0.344 & 0.065 & 0.355 & - & 0.459 & 2.079 \\
\hline
\end{tabular}

*SD - standard deviation $(\mathrm{n}=3)$; ** BQL - peak detected, concentration lower than the LOQ but higher than the LOD; ***ND - peak not detected, quercitrin and tiliroside not found in any sample
4. Siegrist M, Shi J, Giusto A, Hartmann C. Worlds apart. Consumer acceptance of functional foods and beverages in Germany and China. Appetite 2015; 92: 87-93.

5. Mościcki L. Extrusion-Cooking Techniques. Weinheim, Germany: Wiley-vch Verlag \& Co.KGaA, 2011.

6. Singh S, Gamlath S, Wakeling L. Nutritional aspects of food extrusion: a review. Int J Food Sci Tech. 2007; 42: 916-929.

7. Wójtowicz A, Mościcki L. Influence of extrusion-cooking parameters on some quality aspects of precooked pasta-like products. J Food Sci. 2009; 74: 226-233.

8. Harper JM. Food extruders and their applications. Cereal Chemists. IARC, International Agency for Research on Cancer. Aflatoxins. In Some naturally occurring substances: Food items and constituents, heterocyclic aromatic amines and mycotoxins in IARC monograph on the evaluation of carcinogenic risks to humans. 1993; 56: 245. Lyon, France: World Health Organization/IARC.

9. Zemestani M, Rafraf M, Asghari-Jafarabadi M. Chamomile tea improves glycemic indices and antioxidants status in patients with type 2 diabetes mellitus. Nutrition 2016; 32: 66-72.

10. Tadbir AA, Pourshahidi S, Ebrahimi H, Hajipour Z, Memarzade MR, Shirazian S. The effect of Matricaria chamomilla (chamomile) extract in Orabase on minor aphthous stomatitis, a randomized clinical trial. J Herb Med. 2015; 5: 71-76.

11. Najda A, Dyduch-Siemińska M, Dyduch J, Gantner M. Comparative analysis of secondary metabolites contents in Fragaria vesca L. fruits. Ann Agric Environ Med. 2014; 21 (2): 339-343.

12. Oniszczuk A, Wojtunik K, Oniszczuk T, Wójtowicz A, Mościcki L, Waksmundzka-Hajnos M. Radical Scavenging Activity of Instant Grits with Addition of Chamomile Flowers Determined by TLC-DPPH Test and by Spectrophotometric Method. J Liq Chromatogr R T. 2015; 38(11): 1142-1146.

13. Petronilho S, Maraschin M, Coimbra MA, Rocha SM. In vitro and in vivo studies of natural products: A challenge for their valuation. The case study of chamomile (matricariarecutita L.). Ind Crop Prod. 2012; 40:1-12.

14. Maschi O, Dal Cero E, Galli GV, Caruso D, Bosisio E, Dell'Agli M. Inhibiton of human cAMP-phosphodiesterase as a mechanism of spasmolytic effect of Matricariarecutita L. J Agric Food Chem. 2008; 56: 5015-20.

15. Oniszczuk A, Podgórski R, Oniszczuk T, Żukiewicz-Sobczak W, Nowak R, Waksmundzka-Hajnos M. Extraction methods for the determination of phenolic compounds from Equisetum arvense L. herb. Ind Crops Prod. 2014; 61: 377-381

16. Oniszczuk A, Podgórski R. Influence of different extraction method on quantification of selected flavonoids and phenolic acids from Tilia cordata inflorescence. Ind. Crops Prod. 2015; 76: 509-514.

17. Oniszczuk A, Wójtowicz A, Oniszczuk T, Olech M, Nowak R, Wojtunik K, Klimek M, Krawczyk W, Hajnos M. Extruded corn gruels containing linden flowers: quantitation of phenolic compounds and selected quality characteristics. Open Chem. 2015; 13: 1209-1217.

18. Wianowska D, Hajnos ME, Dawidowicz AL, Oniszczuk A, Waksmundzka-Hajnos M, Głowniak K. Extraction methods of 10-deacetylbaccatin III, paclitaxel, and cephalomannine from Taxus baccata L. twigs: A comparison. J Liq Chrom Related Tech. 2009; 32: 589-601.

19. Nowacka N, Nowak R, Drozd M, Olech M, Los R, Malm A. Analysis of phenolic constituents, antiradical and antimicrobial activity of edible mushrooms growing wild in Poland. LWT - Food Sci Technol. 2014; 59: 689-694.

20. Jindal A, Kumar P. Antimicrobial flavonoids from Tridax procumbens. Nat Prod Res. 2012; 26 (22): 2072-2077.

21. Romagnolo DF, Selmin O I. Flavonoids and cancer prevention: A review of the evidence. J Nutr Gerontol Geriatr. 2012; 31 (3): 206-238.

22. Peluso I, Miglio C, Morabito G, Ioannone, F, Serafini M. Flavonoids and immune function in human: A systematic review. Crit Rev Food Sci Nutr. 2015; 55(3): 383-395.

23. Dziki D, Różyło R, Gawlik-Dziki U, Świeca M. Current trends in the enhancement of antioxidant activity of wheat bread by the addition of plant materials rich in phenolic compounds. Trends Food Sci Techn. 2014; 40: 48-61.

24. Guaman-Balcazar MC, Setyaningsih W, Palma M, Barroso CG. Ultrasound-assisted extraction of resveratrol from functional foods: Cookies and jams. Appl Acoust. 2016; 103: 207-213.

25. Chemat F, Tomao V, Virot M,. Ultrasound-assisted extraction in food analysis. In Handbook of food analysis instruments by Semih Ötles. 2008; Boca Raton, Florida, USA: CRC press.

26. Rostagno M.A, Palma M, Barroso, CG. Ultrasound-assisted extraction of soy isoflavones. J Chrom A 2003; 1012: 119-128. 
27. Sun Y, Liu D, Chen J, Ye X, Yu D. Effects of different factors of ultrasound treatment on the extraction yield of the all-trans-b-carotene from citrus peels. Ultrason Sonochem. 2011; 18: 243-249.

28. Khan MK, Abert-Vian M, Fabiano-Tixier AS, Dangles O, Chemat F. Ultrasound-assisted extraction of polyphenols (flavanone glycosides) from orange (Citrus sinensis L.) peel. Food Chem. 2010; 119: 851-858.

29. Melecchi MIS, Peres VF, Dariva C, Zini CA, Abad FC, Martinez MM. Optimization of the sonication extraction method of Hibiscus tiliaceus L. flowers. Ultrason. Sonochem. 2006; 13: 242-250.

30. Wang X, Wu Y, ChenG, Yue W, Liang Q, Wu Q. Optimisation of ultra-sound assisted extraction of phenolic compounds from Sparganii rhizoma with response surface methodology. Ultrason Sonochem. 2013; 20: 846-854.
31. Bajerová P, Adam M, Bajer T, Ventura K. Comparison of various techniques for the extraction and determination of antioxidants in plants. J Sep Sci. 2014; 37: 835-844.

32. Majd MH, Rajaei A, Bashi DS, Mortazavi SA, Bolourian S. Optimization ofultrasonic-assisted extraction of phenolic compounds from bovine pennyroyal (Phlomidoschema parviflorum) leaves using response surface methodology. Ind Crops Prod. 2014; 57: 195-202.

33. Da Porto C, Porretto E, Decorti D. Comparison of ultrasound-assisted extraction with conventional extraction methods of oil and polyphenols from grape (Vitis vinifera L.) seeds. Ultrason Sonochem. 2013; 20: $1076-1080$ 